\title{
Lightning Safety for Florida Agriculture Workers ${ }^{1}$
}

\author{
Shawn Steed and Alicia Whidden²
}

Lightning is a common occurrence in the Sunshine State. Florida is known as the lightning capital of the US and ranks number 1 in lightning-caused deaths (Curran 2000). As Floridians, we have grown accustomed to living with lightning and possibly complacent about its destructive force. Lightning causes about $\$ 5$ billion worth of damage and kills an average of 50 people in the US each year (National Lightning Safety Institute 2008). Although lightning kills only about $10 \%$ of the people it strikes, it can cause physical and mental complications that victims must face for the rest of their lives. As agriculture workers, we need to have a good working knowledge of lightning, its effects, and ways to protect others and ourselves from this potentially life-threatening hazard.

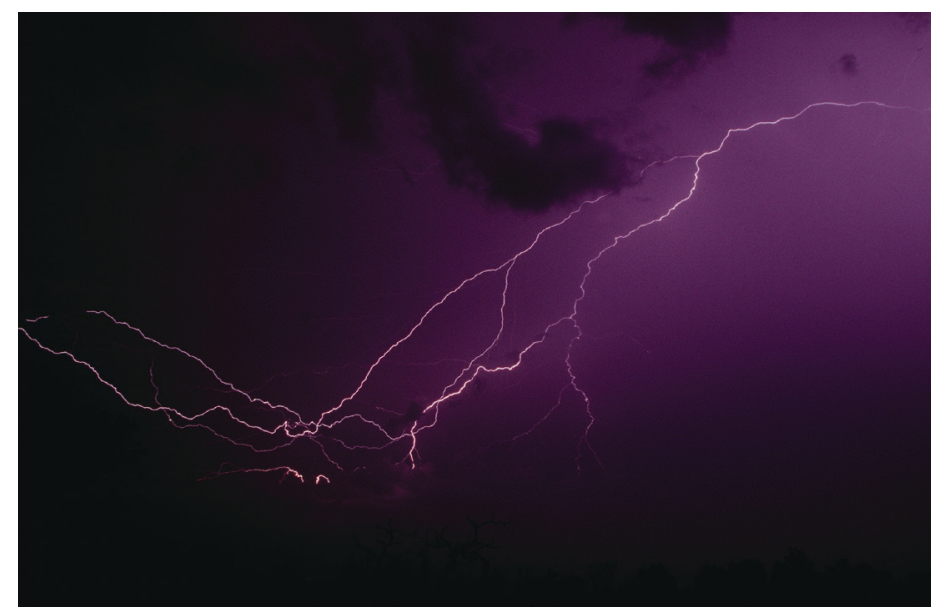

Figure 1. Lightning streaking across a sky.

Credits: UF/IFAS

\section{Types of Lightning}

Lightning occurs when electrical charges build up in clouds from the movement of ice and water particles. The charges seek to neutralize, resulting in a discharge of electrical current known as a lightning strike or flash. Lightning is extremely hot-around $54,000^{\circ} \mathrm{F}$ - and very narrow-less than an inch wide. A lightning strike averages around five miles in length, but a 118-mile-long strike has been recorded. It can strike from a seemingly blue sky from a distant storm - the so-called "bolt from the blue." There are multiple ways a person can be struck by lightning, depending on the way the lightning strike travels:

- Direct strike-This is when a person becomes a part of the main lightning discharge channel. This is usually not common, but it can be the most deadly.

- Side flash-This occurs when lightning strikes a nearby taller object and some of the discharge from the lightning jumps from the taller object to the victim. Generally, the victims are within one or two feet of the taller object. This is why you should not stand under a tree when a storm is approaching.

- Ground current-This is when lightning travels outwards and around from a direct strike. A person affected by ground current is struck by the peripheral movement of lightning in or along the ground surface. An example of this is when lightning strikes a wet golf course and nearby players are injured from contact with the wet ground.

1. This document is AE526, one of a series of the Department of Agricultural and Biological Engineering, UF/IFAS Extension. Original publication date October 2018. Visit the EDIS website at https://edis.ifas.ufl.edu for the currently supported version of this publication.

2. Shawn Steed, environmental horticulture production Extension agent III; and Alicia Whidden, small fruit and vegetable Extension agent III, UF/IFAS Extension Hillsborough County; UF/IFAS Extension, Gainesville, FL 32611.

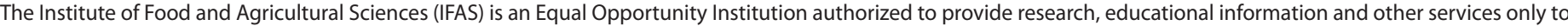

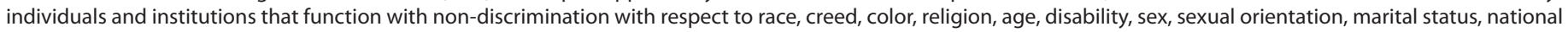
origin, political opinions or affiliations. For more information on obtaining other UF/IFAS Extension publications, contact your county's UF/IFAS Extension office. 
Ground current affects a much larger area and causes the most lightning deaths and injuries.

- Conduction-This is when lightning travels long distances through wires or other metal surfaces. Lightning can follow a path along metal fence lines, wires, plumbing, corded phones, windows and doors, and water. Conduction causes most indoor lightning casualties.

- Streamers-These are usually upward-reaching charges that seek a connection with the downward-reaching main stepped leader. Streamers can originate from charged objects in the nearby path of lightning. People located in the path of streamers can get struck.

For more information, visit https://www.weather.gov/safety/ lightning-struck (National Weather Service n.d.).

\section{Lightning in Florida}

The area between Tampa and Orlando-sometimes referred to as "Lightning Alley"-is known to be a very active area for lightning activity. High daytime temperatures in this area, coupled with a moisture-laden atmosphere and the collision of sea breezes, lead to many afternoon thunderstorms with lots of lightning. Lightning activity in Florida tends to have an annual cycle. There is a rapid increase in May, a peak in July, and then a rapid decrease in September. The flash rate continues to decline through the winter, with January being the most inactive period. In a 24-hour cycle, more lightning will occur during afternoon and early evening between 12:00 and 8:00 p.m., with the peak around 4:00 p.m. (Orville and Huffines 2001).

\section{Outdoor Safety for Farm Workers}

When lightning is nearby, workers should avoid open areas, such as fields, construction sites, and recreation sites, and bodies of water, such as oceans, lakes, swimming pools, irrigation ditches, and retention ponds. High places or tall structures, such as tops of buildings, greenhouses, trees, or scaffolds, should be avoided. Employees should not seek shelter under trees or small open structures, such as rain shelters, picnic shelters, gazebos, or open equipment sheds. Employees should also avoid bleachers (metal or wood), metal fences, and metal objects, such as carts, wheelbarrows, telephone lines, pipelines, cables, or steel fabrications. Employees should refrain from leaning against or sitting on cars, bicycles, motorcycles, or tractors. They should also avoid holding metal objects, such as tools, rakes, shovels, pole pruners, etc., that might transmit lightning from the ground or other objects to themselves. The National Weather Service used to recommend a "lightning safe crouch." However, it now states that there is no safe place outside during a lightning storm. Every effort should be made to avoid a dangerous situation. However, if you cannot reach a safe structure in time:

- Avoid open areas.

- Do not be or be near the tallest objects in the area.

- Do not shelter under tall or isolated trees.

- In the woods, put as much distance as you can between you and any tree.

- Spread out (if in a group) so that you increase the chances for survivors who could come to the aid of any victims from a lightning strike.

\section{Lightning Medical Aid}

Lightning causes nervous system injury and may affect the brain, autonomic nervous system, and peripheral nervous system. Remember that injured persons struck by lightning do not carry an electrical charge. If someone is struck by lightning, call 911 and administer first aid as quickly as possible. If more than one person is struck by lightning, administer to those who are unresponsive first. If they are unconscious, check for breathing and pulse. If they have a pulse, but are not breathing, begin cardiopulmonary resuscitation (CPR). Most fatalities in lightning strikes are caused by cardiac arrest and/or cessation of breath (National Weather Service n.d.). If the victim is responsive, check for other injuries, keep them calm, and stay with them until help arrives. Lightning strike victims can suffer lifelong neurological problems. Symptoms include loss of short-term memory, problems sleeping, physical disabilities, reduced attention span, chronic pain, dizziness, chronic fatigue, and personality changes (Cooper 1995).

\section{Regulations for Employers}

The Occupational Safety and Health Administration (OSHA), which regulates employee safety while at work, requires that employers maintain safe working conditions for all employees (General Duty Clause, Section 5(a) (1) of OSH Act). Lightning is viewed as a dangerous workplace condition that needs to be mitigated, especially for employees working outside. Although OSHA does not publish specific criteria about protocols for dealing with lightning, it recognizes that implementing a lightning safety protocol (LSP) as part of an emergency action plan can protect workers (OSHA and NOAA n.d.). In agricultural settings, OSHA does not have specific regulations about lightning as in other regulated industries; however, it would view employee safety through the lens of the General Duty 
Clause, meaning that employees must be protected from lightning hazards at the workplace.

An effective LSP should ensure all employees, supervisors, and workers know the hazards of lightning and receive adequate training in lightning safety from employers. Employers should post information about lightning safety at outdoor worksites. A lightning protocol should include a way of determining when lightning is in an area. This could be a lightning detection device or service (Kithil 2018), a weather alert phone app, or something as simple as listening for thunder. The work environment will dictate the type of alert system used to protect employees. The second step in the plan should discuss how employees are notified and what precautions employees should take when lightning is detected in the area. This part of the plan should designate someone who will notify employees of an approaching lightning hazard, and identify where to find safe locations and how much time it will take to reach them. Safe places and routes should be planned in advance. A safe structure is one that is enclosed and has plumbing or electrical wiring, windows, and doors. Some solid structure greenhouses may be considered safe, but most greenhouses would provide insufficient protection for employees during a lightning event. Open structures, such as pavilions, open-roofed structures, or shade houses, are not safe. If employees are out in the field and cannot get to a safe structure, OSHA considers enclosed vehicles as safe structures, as long as they are completely enclosed (windows and doors closed) and employees are not touching electrical components. The next part of the protocol should determine when conditions are deemed unsafe for work and safe to return to work as an electrical storm approaches and passes. A good rule of thumb is the 30 -second, 30 -minute rule: 30 seconds from flash to bang (seeing lightning to hearing thunder) is a general guide for when workers should seek safe shelter. Thunder travels approximately one mile in five seconds. A 30-second interval between lightning and thunder means that the lightning struck about six miles away. This interval might be longer if there is a fast-moving storm in the area. After the storm's passing, if there has been no thunder for 30 minutes, workers can consider returning to work.

Working outdoors has its rewards and challenges. Lightning can be counted as one of the more serious risks. Farming operations in Florida should take this risk seriously and have a good lightning procedure protocol in place to protect their employees from harm. It is important for outdoor workers, namely agricultural workers, to take lightning precautions seriously and react quickly. Many individuals in the US who did not survive lightning strikes were either seeking shelter or steps away from shelter (Jensenius, Jr. 2018). Keep this simple saying in mind: "When thunder roars, go indoors" (MPSS n.d.).

\section{Lightning Quick Facts}

Florida ranks number 1 in the number of lightning-caused deaths.

Between 2006 and 2017, agricultural work had the highest percentage (26\%) of work-related deaths (Jensenius, Jr. 2018).

Lightning can strike from as far as 10 miles away.

Thunder travels one mile in five seconds.

Who gets struck? $84 \%$ male; $16 \%$ female (Jensenius, Jr. 2018).

Lightning casualties by activity: $63 \%$ leisure activities (water-related: $21 \%$, sports: $14 \%$ ); $17 \%$ work activities (farming/ranching: $4 \%$, construction: $3 \%$, roofing: $3 \%$ ); $16 \%$ daily routine activities; $4 \%$ unknown (Jensenius, Jr. 2018).

1 in 3,000: a person's odds of being struck by lightning. $90 \%$ survival rate if treated quickly.

Months with the most lightning activity: June (21\%), July (30\%), August (22\%) (Jensenius, Jr. 2018).

Each year in the US, lightning causes an average of 50 deaths and $\$ 5$ billion in damage (National Weather Service n.d.).

\section{References}

Cooper, M. A. 1995. "Emergent care of lightning and electrical injuries.” Sem. in Neurology 15(3). https://lightninginjury.lab.uic.edu/treatment.html

Crisp, B. n.d. "When lightning strikes." Archived. UF/ IFAS Extension Pasco County. Accessed on January 7, 2016. http://pasco.ifas.ufl.edu/fcs/Lightning.shtml

Curran, E. B., R. L. Holle, and R. E. López. 2000. "Lightning casualties and damages in the United States from 1959 to 1994." Journal of Climate 13: 3448-3453.

Jensenius, Jr., J. S. 2018. “A detailed analysis of lightning deaths in the United States from 2006 through 2017." National Weather Service, National Oceanic and Atmospheric 
Administration. Accessed on September 13, 2018. https:// www.weather.gov/media/safety/06-17lightning_fatality_analysis.pdf

Kithil, R. 2018. "Overview of lightning detection equipment." National Lightning Safety Institute. Accessed on September 12, 2018. http://lightningsafety.com/nlsi_lhm/ detectors.html

MPSS. n.d. "Institute of Occupational Safety and Health: Safety Training Presentations-Lightning safety awareness." Accessed on September 12, 2016. https://www.osha.gov/ dte/grant_materials/fy11/sh-22297-11/LightningSafety.ppt

National Lightning Safety Institute. 2008. "Lightning costs and losses from attributed sources." NLSI. Accessed on September 25, 2018. http://lightningsafety.com/nlsi_lls/ nlsi_annual_usa_losses.htm

National Weather Service. n.d. Lightning Safety Tips and Resources. Accessed on January 7, 2016. http://www. lightningsafety.noaa.gov/index.shtml

National Weather Service. n.d. "Lightning science: Five ways lightning strikes people.” Accessed on September 25, 2018. https://www.weather.gov/safety/lightning-struck

Orville, R. E. and G. R. Huffines. 2001. “Cloud-to-ground lightning in the United States: NLDN results in the first decade, 1989-1998." Monthly Weather Review 129(5): 1179-1193.

OSHA. n.d. "Fatality and Catastrophe Investigation Summaries." United States Department of Labor. Accessed on October 4, 2018. https://www.osha.gov/pls/imis/accidentsearch.html

OSHA and NOAA. n.d. "Lightning safety when working outdoors." Occupational Safety and Health Administration. Accessed on September 12, 2016. https://www.osha.gov/ Publications/OSHA3863.pdf

OSHA Emergency Action Plan. n.d. "29 CFR 1910.35.” Accessed on September 12, 2016. https://www.gpo.gov/ fdsys/pkg/CFR-2011-title29-vol8/pdf/CFR-2011-title29vol8-sec1926-35.pdf

Whidden, A. 2007. "From your agent... Lightning facts and safety tips." Berry/Vegetable Times: Summer 2007. UF/IFAS Extension. Accessed on October 4, 2018. https://gcrec.ifas. ufl.edu/static/docs/pdf/strawberry-vegetable-times/2007/ BVTSummer07.pdf

\section{Additional Information for Employers}

The Occupational Safety and Health Administration (OSHA) is the governing body which protects employees from workplace hazards. Lightning is considered a hazard. OSHA does not have a standard lightning safety mitigation plan to give employers to follow. However, employers should have a plan in place. Here are a few examples of failures to protect employees from lightning.

\section{Citation 316028653/01001}

Company did not follow its own lightning procedures. An employee was struck by lightning when employees were not informed to initiate rides' shutdown procedure after the employer's strike monitoring system indicated activity within zero to five miles of the park (OSHA n.d.).

Citation 486798.015/01001

Employees were exposed to electrocution while taking shelter in ungrounded wooden shack (restrooms) during a lightning storm. Fifteen ground maintenance employees sustained injuries from lightning strikes while taking shelter in a wooden shack that was not provided with any means to deflect or absorb lightning (OSHA n.d.).

Citation 314388406/01001

Aircraft mechanics were ordered to tow an aircraft into a hangar after Andrews Air Force Base had issued a warning of lightning within five miles, which requires that all flight line aircraft maintenance operations be curtailed and personnel seek shelter (OSHA n.d.).

\section{Citation 985948.015/01001}

At a construction site, the employer failed to provide/implement a lightning warning system for employees who were exposed to the hazard of being struck by lightning while working outdoors (OSHA n.d.).

Citation 978865.015/01001

Employer exposed employees to the hazard of being struck by lightning while pumping concrete on a roof of a building in the rain (OSHA n.d.). 